\title{
Parametric Investigation of Seismic Interaction between Precast Concrete Cladding Systems and Moment Resisting Frames
}

\author{
Andrew Baird ${ }^{1}$, Riccardo Diaferia ${ }^{2}$, Alessandro Palermo ${ }^{3}$, Stefano Pampanin ${ }^{4}$ \\ ${ }^{1}$ PhD Candidate, Dept. of Civil and Natural Resources Engineering, University of \\ Canterbury, P.O. Box 4800, Christchurch 8140, New Zealand; PH (+64) 27- \\ 6961791; email: andrew.baird@pg.canterbury.ac.nz \\ ${ }^{2}$ Master student, Dept. of Civil Engineering, Politecnico di Milano, Campus \\ Leonardo, Milano, Italy; PH (+39)328-3934441; email: rikdia@hotmail.it \\ ${ }^{3}$ Senior Lecturer, Dept. of Civil and Natural Resources Engineering, University of \\ Canterbury, P.O. Box 4800, Christchurch, 8140 New Zealand; PH (+64) 21- \\ 2370407; email: alessandro.palermo@canterbury.ac.nz \\ ${ }^{4}$ Associate Professor, Dept. of Civil and Natural Resources Engineering, University \\ of Canterbury, P.O. Box 4800, Christchurch 8140, New Zealand; PH (+64) 21- \\ 2370407; email: stefano.pampanin@canterbury.ac.nz
}

\begin{abstract}
This paper presents the results of a preliminary numerical investigation into the interaction between precast concrete cladding systems and moment resisting frames. Macro-scale models of cladding systems are implemented in existing lumped plasticity models for moment resisting frames. Different failure mechanisms and various configurations are considered in order to show the effect of the entire cladding system upon a structure's seismic behavior. Several parameters are varied in order to establish their associated influence on the overall structural response. Results show that it is clearly more advantageous to have a failure mechanism governed by the connection than one governed by either the panel or the frame.

An experimental program is now underway building on what has been learnt from the parametric investigation. The authors intend to continue the research to successively develop improved or innovative low-damage cladding-moment resisting frame systems. They also aim to produce simple design tools that provide easy inclusion of the seismic effects of cladding-frame interaction.
\end{abstract}




\section{INTRODUCTION}

The response of non-structural components can significantly affect the functionality of a building after an earthquake, even when the structural members are left undamaged. The poor performance of non-structural components or secondary structural elements in past earthquakes has led to buildings being left unoccupied, resulting in substantial economic losses due to business interruption. Furthermore, damage to non-structural components, such as that shown in Figure 1, can pose a serious risk to the safety of people inside and outside the building (Charleson, 2008). Recent earthquakes in L'Aquila, Italy (6 April 2009), Concepcion, Chile (27 February 2010) and Darfield, New Zealand (4 September 2010) have further highlighted the severe impact that damage to non-structural elements can have upon the overall recovery effort.

In order to develop and propose practical and efficient solutions that reduce the risk of damage to non-structural components it is necessary to understand how they interact with a structure. In addition, determining which parameters most influence this interaction is essential so that all possible damage and/or failure mechanisms are identified.

This paper presents the preliminary results of a numerical study on the interaction between a precast concrete cladding panel attached to a reinforced concrete moment resisting frame. This is achieved using static push-over and cyclic push-pull analyses of a lumped plasticity model representing an interior single-storey, single bay of a multistorey building. In order to understand the different possible damage and failure mechanisms several parameters of the systems are varied. The results also confirmed the sensitivity of the systems' behavior to such changes.

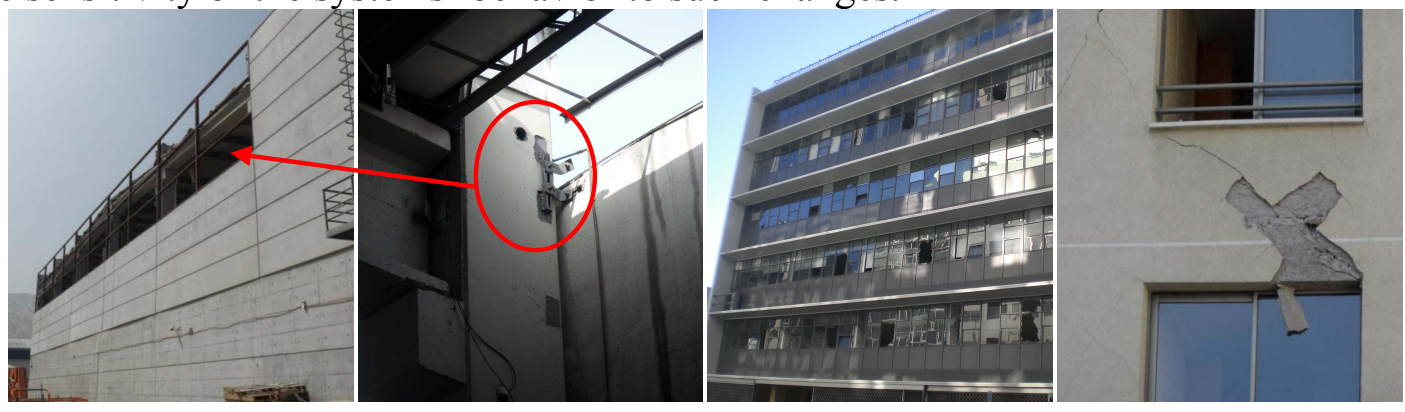

Figure 1: Example of cladding failures

\section{BACKGROUND}

Precast concrete panels are widely used around the world as an exterior cladding for multi-storey buildings. Such cladding can be considered as non load bearing wall systems which are designed primarily to transfer their self-weight and out-of-plane (wind and earthquake) lateral loads to the supporting building structure. The contribution of the cladding system to the lateral stiffness of the building is often ignored in the structural design. However, experimental investigations on newly designed buildings have shown that claddings can contribute significantly to the lateral stiffness of the structure and that the panels can be subjected to significant in-plane forces (Goodno et al., 1988) which might cause unexpected structural failure. In order to avoid this unintended interaction, it is possible to isolate cladding panels, as shown by research using autoclaved lightweight aerated concrete (ALC) panels. ALC panels can be connected using sliding and rotating connections, as shown in Figure 2, such that they contribute very little to the stiffness and strength of the overall structure, even under a very large inter-storey drifts of 0.04 radians (Okazaki et al., 2007). 

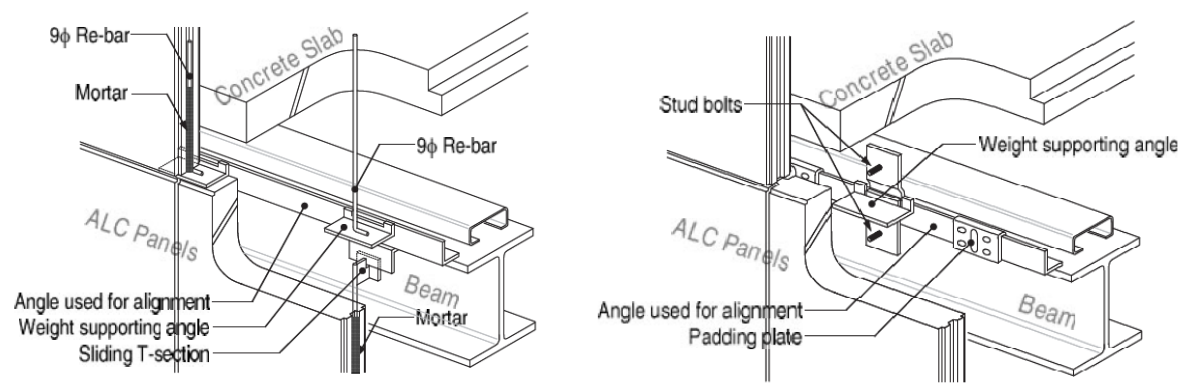

Figure 2: Sliding panel (left) and rotating panel (right), (Okazaki et al., 2007)

Complete isolation with the structural system does however mean that the cladding is simply a dead weight. Consequently, investigations have been carried out into ways in which the structure can profit from having cladding panels attached. If the additional stiffness and strength that cladding panels provide is utilized during design then a savings up to $25 \%$ in the volume of steel used in the structure can be achieved (De Matteis, 2005).

Cladding panels can also be used to provide passive control for the seismic behavior of buildings with the use of energy dissipative connections. Results show that energy dissipative cladding connections like that shown in Figure 3 could provide the total hysteretic energy required of the structural system (Pinelli et al., 1995).
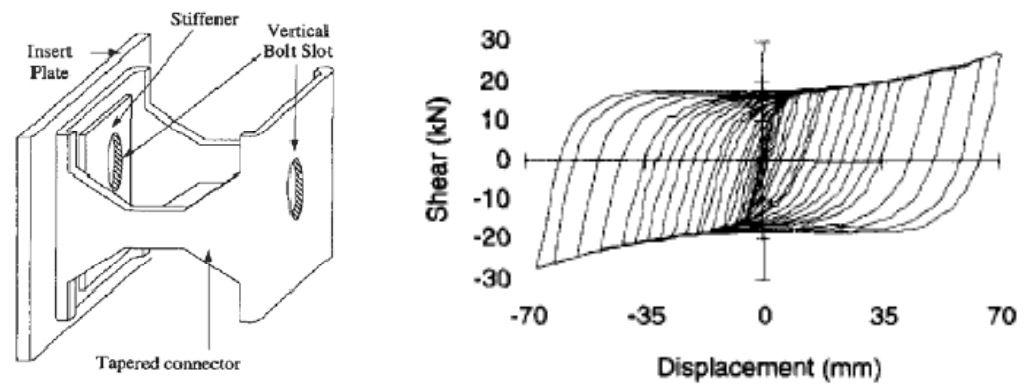

Figure 3: Advanced energy dissipating connection (left) and hysteretic loop (right), (Pinelli et al., 1995)

The main emphasis of research on cladding systems to date is on detailed research into isolated façade technology. This therefore leaves open the question of whether benefits found can be applied should some parameter be slightly different. This paper aims to help in providing a way to broaden the results of such research so it can be applied to a range of similar façade technology.

\section{PERFORMANCE-BASED DESIGN and FAILURE MECHANISMS}

Design for seismic resistance has been undergoing a critical reappraisal in recent years, with the emphasis changing from 'strength' to 'performance'. For most of the past 80 years (the period over which specific design calculations for seismic resistance have been required by codes) strength and performance have been considered to be synonymous (Priestley, 2000). However now, performance based engineering has become a standard norm for research, development and practice of earthquake engineering, particularly after the 1994 Northridge and 1995 Kobe earthquakes (Okazaki et al., 2007). The primary function of performance-based seismic design is the ability to achieve, through analytical tools, a building design that will reliably perform in a prescribed manner under one or more seismic hazard conditions. The performance, 
or condition of the building as a whole, is typically expressed through qualitative terms, intended to be meaningful to the general public. These terms use general terminology and concepts describing the status of the facility (i.e. Fully Operational, Operational, Life Safety and Near Collapse) but should also be associated and linked to appropriate technically-sound engineering terms and parameters. These performance-based design criteria are applicable to both structural and non-structural elements. Table 1 provides descriptions of the damage associated with three performance levels for two façade elements.

Table 1: Suggested performance levels (FEMA 356, 2000) and seismic design performance matrix (SEAOC Vision 2000 Committee, 1995)

\begin{tabular}{|c|c|c|c|}
\cline { 2 - 4 } \multicolumn{1}{c|}{} & \multicolumn{2}{c|}{ PERFORMANCE LEVEL } \\
\hline Element & $\begin{array}{c}\text { Collapse } \\
\text { Prevention }\end{array}$ & Life Safety & $\begin{array}{c}\text { Immediate } \\
\text { Occupancy }\end{array}$ \\
$\begin{array}{c}\text { Precast } \\
\text { Pancrete }\end{array}$ & $\begin{array}{c}\text { Some } \\
\text { connection } \\
\text { failure but no } \\
\text { elements } \\
\text { dislodged. }\end{array}$ & $\begin{array}{c}\text { Local crushing, } \\
\text { spalling at } \\
\text { connections, but no } \\
\text { gross failure. }\end{array}$ & $\begin{array}{c}\text { Minor } \\
\text { working at } \\
\text { connections, } \\
\text { crack width } \\
<1.5 \mathrm{~mm}\end{array}$ \\
\hline \multirow{2}{*}{ Cladding } & $\begin{array}{c}\text { Severe } \\
\text { damage to } \\
\text { connections } \\
\text { and cladding. } \\
\text { Many panels } \\
\text { loosened. }\end{array}$ & $\begin{array}{c}\text { Severe distortion in } \\
\text { connections. } \\
\text { Distributed } \\
\text { cracking, bending, } \\
\text { crushing and } \\
\text { spalling of } \\
\text { claddings }\end{array}$ & $\begin{array}{c}\text { Connections } \\
\text { yield; minor } \\
\text { cracks } \\
(<1.5 \text { mm } \\
\text { width }) \text { or } \\
\text { bending in } \\
\text { cladding. }\end{array}$ \\
\hline
\end{tabular}

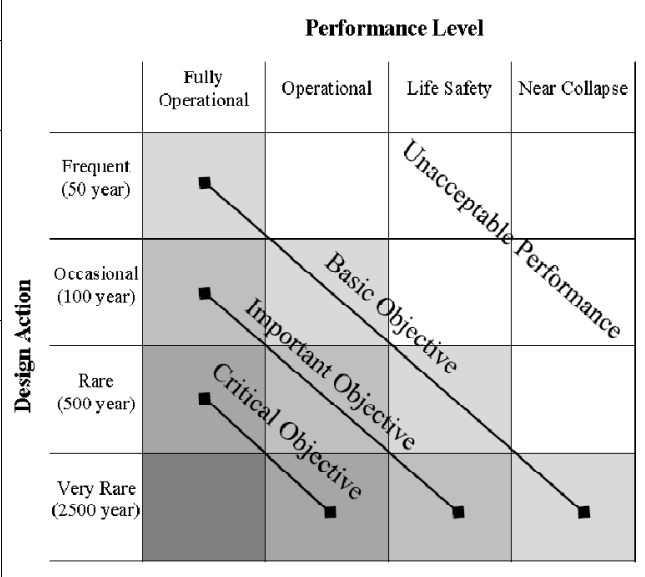

\section{Seismic Performance and Failure Mechanisms for Façade Systems}

In assessing the overall performance of a building, traditional design methods tend to consider the structural and the non-structural systems separately. When the behavior of the bare structure is affected by the interaction with the façade, e.g. additional stiffening and hysteretic damping, then it becomes more appropriate to assess the performance of the combined system rather than the systems separately. Both of these approaches are depicted below in Figure 4 using a simplified chain diagram.

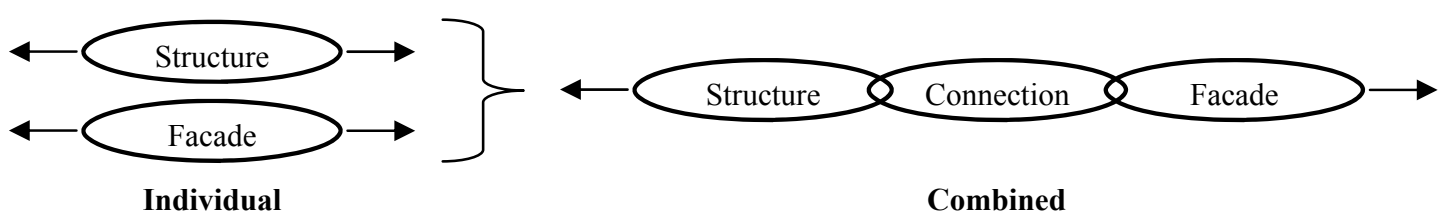

\section{Figure 4: Simplified diagram for structure-façade system of a building}

When a combined system approach is taken, capacity design principles can be used to define a number of different scenarios of failure, as depicted in Figure 6. Assuming that the cladding system is comprised of a structural frame member, a connector body and cladding panel, linked together with strong and stiff attachments, as shown in Figure 5, then the problem can be simplified in order to determine where failure is most likely to occur. An advanced performance-based design would thus target the most desirable hierarchy of strength and sequence of events of the overall system.

If the in-plane strength of the cladding panel is greater than that of the connector body, then the connector body (weakest link of the chain) is expected to govern the 
overall cladding failure mechanism. Conversely, if the connector body is stronger than the panel, then failure is governed by the panel strength which becomes this time the weakest link of the chain. For the above two scenarios it is assumed that the attachment of the connector body is stronger than both the cladding and the connector body itself. Despite the simplicity of these design principles, errors have been made in the past where the attachment ends up being the weakest link in the system. When the attachment governs the failure then the risk of falling panels is very high. From herein the connector body is referred to as the 'connection'.

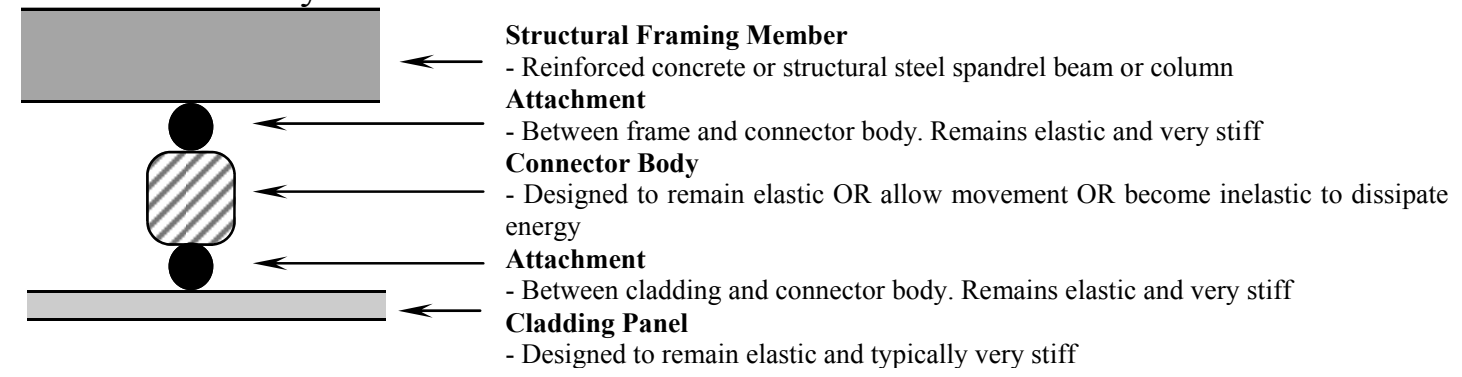

Figure 5: Structure - cladding system (Cohen, 1993)

There is also the highly undesirable case where the panel, connector and attachments are stronger than the frame member and failure occurs in structural members due to local interaction. This scenario is only possible if concrete panels might be adopted and designed with the intention to behave as a structural wall.

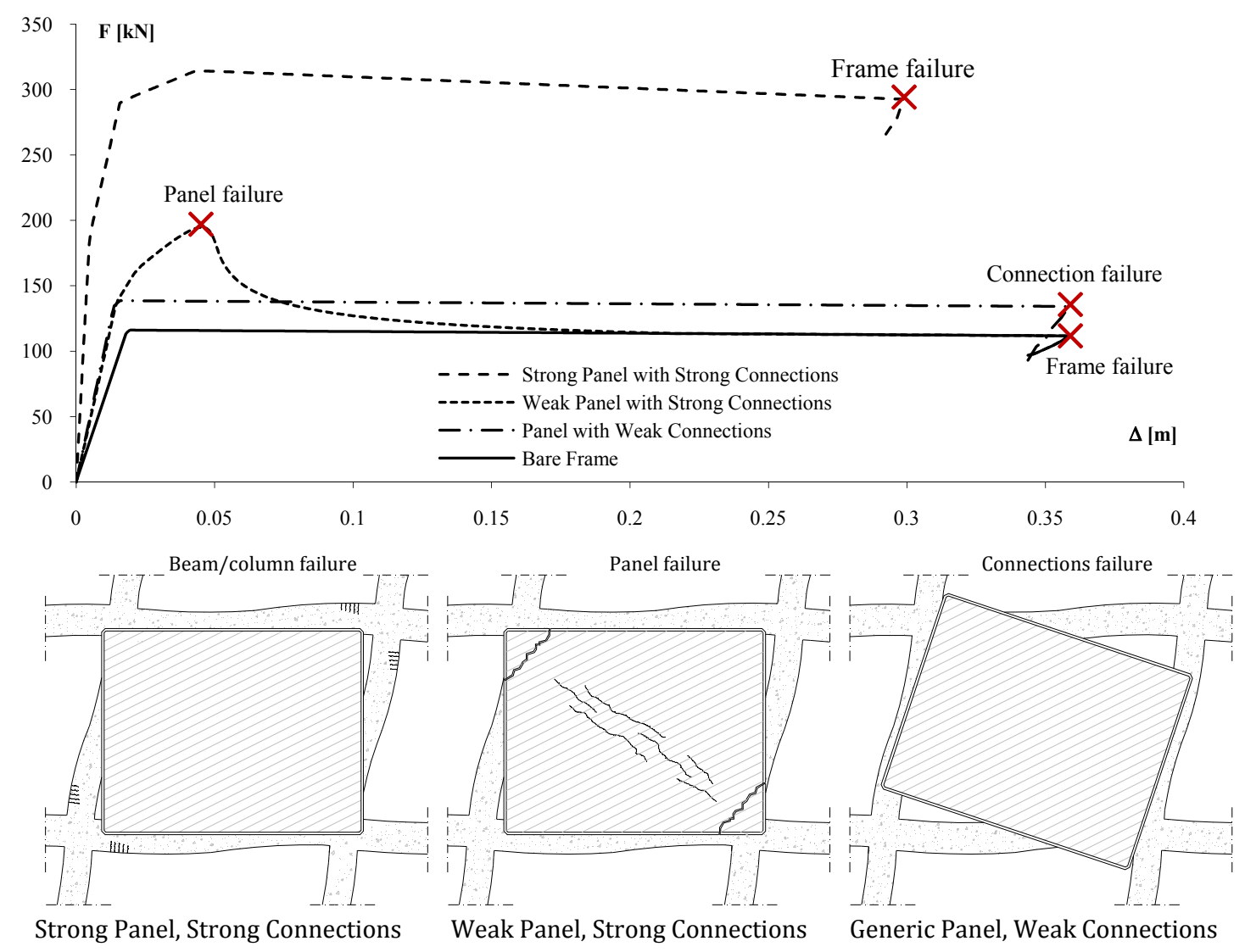

Figure 6: Different failure mechanisms and push-over behaviour of precast panels attached to a frame system 


\section{NUMERICAL INVESTIGATION}

The numerical investigation has been considered using a monolithic single bay, singly storey reinforced concrete frame with the presence of a single precast concrete cladding panel. The setup is based on a corresponding experimental program that is currently undergoing considering cladding typologies and various cladding panel/connection configurations. The frame is designed in accordance with capacity design principles and the cladding system is designed considering the drift limits at Serviceability Limit State (SLS) and at Ultimate Limit State (ULS).

The numerical investigation only considers a single panel and all openings in the panels are herein neglected. The model has been implemented using the program RUAUMOKO (Carr, 2004), based on a lumped plasticity model, with the beams and columns represented by elastic elements with inelastic behavior concentrated in plastic hinge regions (Giberson model) and defined by the moment curvature hysteresis rule 'Modified Takeda' (Otani, 1974).

The cladding panel is connected either vertically on the beams or horizontally on the columns. The behavior of the connections is based on experimental testing of several connections used to support precast concrete cladding (McMullin et al., 2004). The panel and connections are modeled with appropriate hysteretic rules which vary case by case. The aim of the numerical investigation is to carry out a sensitivity analysis of the parameters which affect the behavior of the facade-structure system. This will be achieved through a parametric analysis. At the same time, different failure mechanisms of the facade-structure system will be explored.

The investigation is separated into two parts, distinguished by failure mechanism. The first part covers the cases where failure of the cladding connections governs the behavior of the system. The second section covers the cases where the failure of the cladding panel or the frame governs.

\section{Part 1: Connection Governing Model}

The connection governing model has been designed such that yielding of the cladding connection occurs prior to yielding of either the cladding panel or the frame. The connection yield displacement was based on a drift chosen between the range of SLS and ULS. For this example the value used for the yielding drift is $0.3 \%$. Considering commercial connections available, the strength and stiffness of the connections was chosen to satisfy this predetermined limit.

The panel element has four connections; two bearing connections and two tieback connections. The bearing connections are located on the lower half of the panel and are intended to transfer the self weight of the panel to the structure. The tie-back connections are located on the top half and are intended to deform under in-plane loading whilst providing out-of-plane support. Each connection is modeled by a spring member with horizontal and vertical stiffness. For the bearing connections, the connector elements in both horizontal and vertical directions are assumed to be very stiff and very strong. The tie-back connections have lower stiffness and yield strength so these govern the force that the cladding can carry. The model and force displacement behavior are shown in Figure 7.

The tie-back connections are modeled with an elasto-plastic hysteresis rule or bilinear with slackness (representing a slotted connection, which is typically used to also accommodate thermal variations). The use of a perfectly plastic model with no strain hardening is a simplification that is judged reasonable based on the behavior of experimental cladding connector testing (McMullin et al., 2004). 

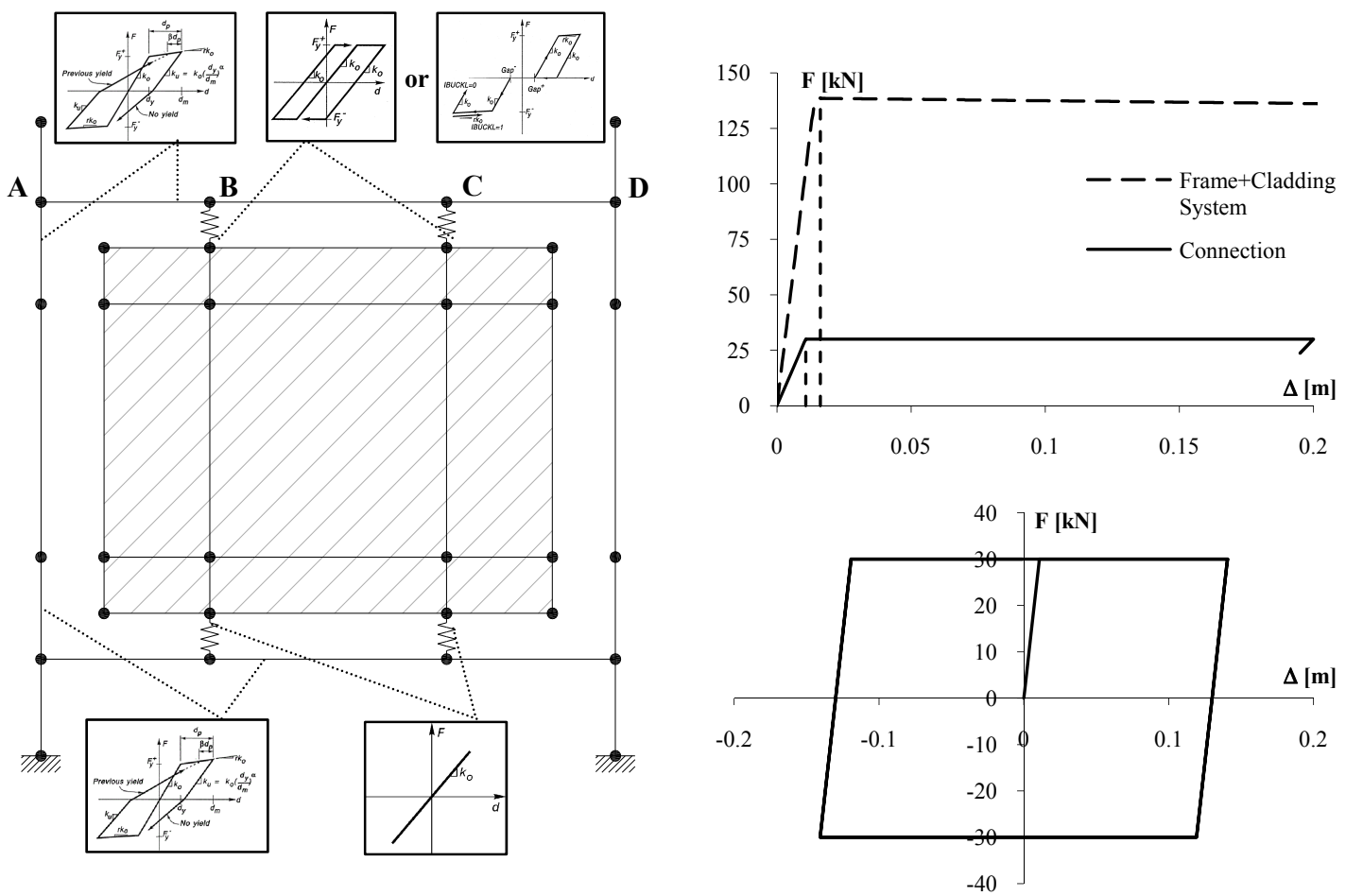

\section{Figure 7: Connection governing model with force displacement behavior}

Since the tie-back connections are significantly weaker and less stiff than the bearing connections, the bearing connections are modeled as elastic. The tie-back connections can also not carry sufficient force for the panel to ever yield, thus the panel is assumed to remain elastic and is represented by an elastic 'quadrilateral' element, as shown in Figure 7 (left), which does not consider post-yielding effects.

\section{Part 2: Panel/Frame Governing Model}

If the cladding connection is assumed to be strong, then the failure mechanism is not governed by the connection but rather by either the panel or the frame. When this is the case it is essential that the panel is modeled with an appropriate non-linear behavior. Diagonal springs representing the compressive struts are herein used as typically done for infill panels. The model and force displacement behavior is shown in Figure 7.

The hysteretic behavior of the diagonal struts is modeled using the Crisafulli hysteresis rule, extensively validated to model stiffness and strength degradation in masonry infill panels (Crisafulli, 1997). The implementation of this rule requires several parameters which are based largely on experimental data. The most critical parameter dictating the behavior of the strut is the compressive strength. This does not represent the standard compressive stress of the concrete but rather of the strut. Hence it should take into account the inclination of the strut and expected mode of failure (Crisafulli, 1997). Accordingly, without experimental data to verify the accuracy for a panel of the particular geometry and reinforcement used, the accuracy of this parameter is, at this stage, likely to be limited. However, it has been assumed that panel failure consists of crushing of the concrete where the strut bottlenecks into where the panel connection is located and values have been used that correspond to such behavior (Brown et al., 2006). Even so, the compressive strength is varied as part of the investigation in order to appreciate the different behavior expected of different strength panels. The model does not take into account possible shear failure mechanism in the joint induced by the panel. 

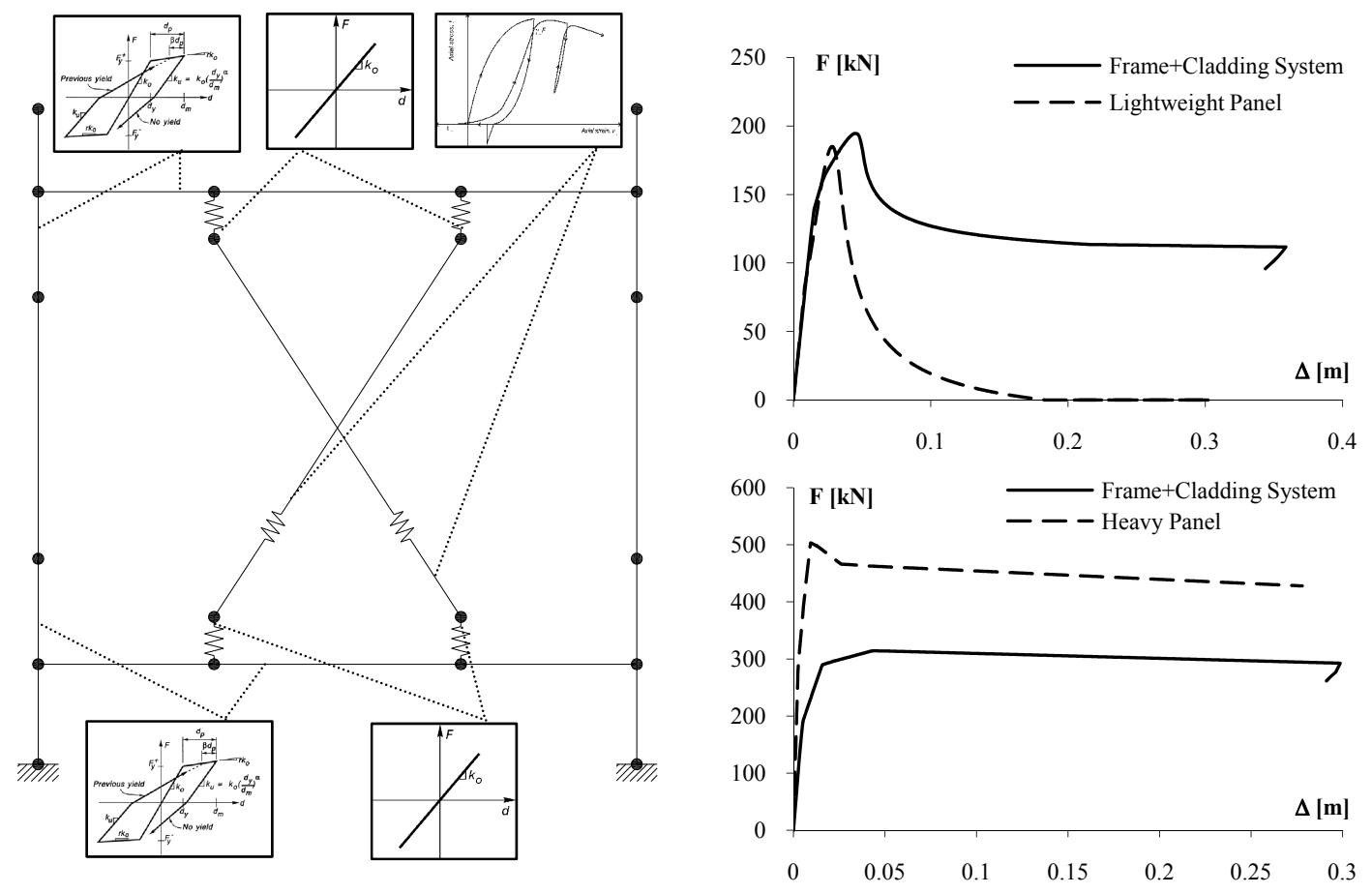

Figure 8: Panel/frame governing model with force-displacement behavior

\section{PARAMETRIC ANALYSIS}

In order to understand the effect that various parameters have upon the behavior and performance of cladding panels under in-plane seismic loading, a multi-parametric analysis has been conducted. The parameters to be varied are based primarily on modifications to typical commercial connections. The analyses consist of push-over and push-pull displacement controlled tests where a monotonic displacement is applied at the top of the column. The push-over analyses aim to reveal the yielding and failure characteristics of both individual components and of the system as a whole. The pushpull analyses are performed at repeating cycles of $4 \%$ drift in order to provide additional information on the hysteretic behavior.

As mentioned in the previous section, the parametric analysis is separated into two groups; those cases where the connection failure governs the interaction between the panel and the frame and the cases where either failure of the panel or frame governs. This means that not all variables are considered in each part of the analyses but only those that are deemed appropriate, e.g. modifying the panel strength is not seen as important when the connection failure governs. Furthermore, modularity of cladding, i.e. panels' configuration, is not considered for sake of brevity.

The following parameters are to be varied:

- Frame height to span ratio $(1: 1,1: 1.5,1: 2)$

- Connection configuration (beam vs. column)

- Connection behavior (fixed vs. slotted)

- Panel type (and strength)

\section{Part 1: Connection Governing Analyses}

The fixed variables for these analyses are the panel type and bearing connection behavior. The panel type is a concrete panel that covers the entire frame bay and is reinforced with steel mesh. Both the panel and the bearing connections are assumed to be stiff and elastic. 


\section{Results}

Shown in Figure 9 are force-displacement plots of the push-over and push-pull analysis results. These particular plots are for a frame ratio of 1:1 with fixed beam connections. The general shape of these plots is similar for all analyses where connection failure governs. The frames base shear and deflection at yield for all of the analyses conducted can be seen in Table 2 in order to compare the results.
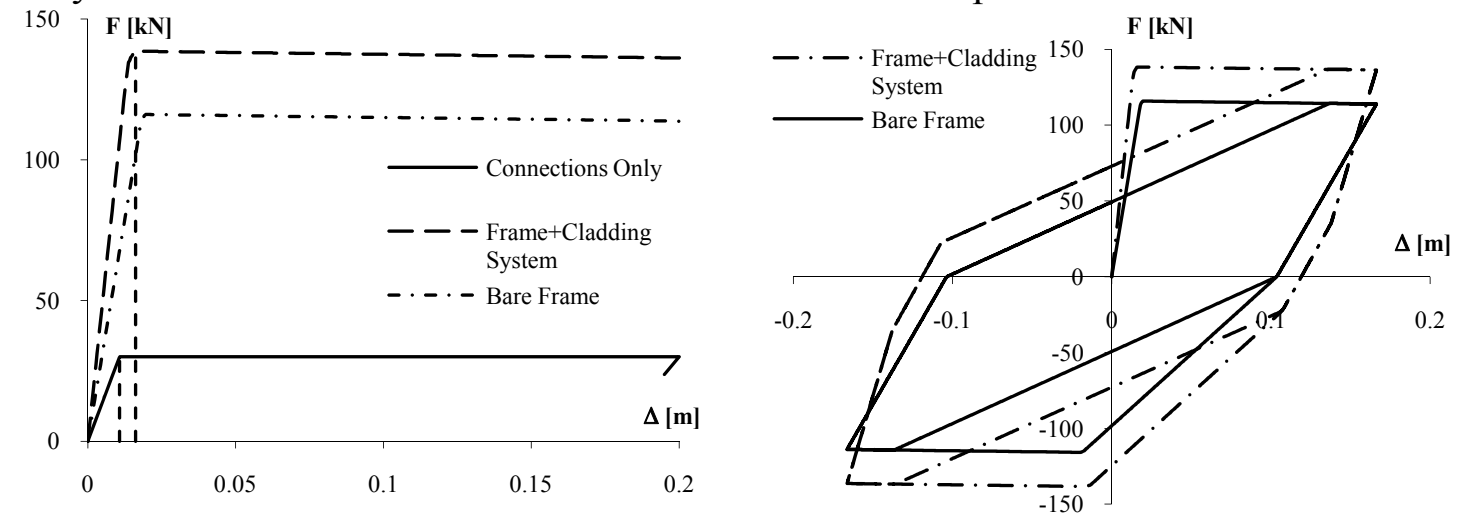

Figure 9: Force-displacement analyses for connection governing cases

Table 2: Parametric results for push-over analyses of connection governing cases

\begin{tabular}{|c|c|c|c|c|c|c|}
\cline { 3 - 7 } \multicolumn{1}{c|}{} & \multicolumn{2}{c|}{ Beam Connections } & \multicolumn{2}{c|}{ Column Connection } \\
\cline { 2 - 7 } \multicolumn{1}{c|}{} & Frame Ratio & Bare Frame & Fixed & Slotted & Fixed & Slotted \\
\hline \multirow{4}{*}{$\begin{array}{c}\text { Base Shear } \\
\text { at Yield }\end{array}$} & $1: 1$ & $115.8 \mathrm{kN}$ & $\begin{array}{c}129.3 \mathrm{kN} \\
(+11.7 \%)\end{array}$ & $\begin{array}{c}129.2 \mathrm{kN} \\
(+11.6 \%)\end{array}$ & $\begin{array}{c}138.3 \mathrm{kN} \\
(+19.4 \%)\end{array}$ & $\begin{array}{c}138.3 \mathrm{kN} \\
(+19.4 \%)\end{array}$ \\
\cline { 2 - 7 } & $1: 1.5$ & $115.8 \mathrm{kN}$ & $\begin{array}{c}129.4 \mathrm{kN} \\
(+11.7 \%)\end{array}$ & $\begin{array}{c}129.3 \mathrm{kN} \\
(+11.7 \%)\end{array}$ & $\begin{array}{c}138.4 \mathrm{kN} \\
(+19.5 \%)\end{array}$ & $\begin{array}{c}138.3 \mathrm{kN} \\
(+19.4 \%)\end{array}$ \\
\cline { 2 - 7 } & $1: 2$ & $115.8 \mathrm{kN}$ & $\begin{array}{c}129.4 \mathrm{kN} \\
(+11.7 \%)\end{array}$ & $\begin{array}{c}129.4 \mathrm{kN} \\
(+11.7 \%)\end{array}$ & $\begin{array}{c}138.4 \mathrm{kN} \\
(+19.5 \%)\end{array}$ & $\begin{array}{c}138.4 \mathrm{kN} \\
(+19.5 \%)\end{array}$ \\
\hline \multirow{4}{*}{$\begin{array}{c}\text { Frame } \\
\text { Deflection } \\
\text { at Yield }\end{array}$} & $1: 1$ & $0.020 \mathrm{~m}$ & $\begin{array}{c}0.021 \mathrm{~m} \\
(+5.0 \%)\end{array}$ & $\begin{array}{c}0.033 \mathrm{~m} \\
(+65.0 \%)\end{array}$ & $\begin{array}{c}0.016 \mathrm{~m} \\
(-20.0 \%)\end{array}$ & $\begin{array}{c}0.020 \mathrm{~m} \\
(+0.0 \%)\end{array}$ \\
\cline { 2 - 7 } & $1: 1.5$ & $0.025 \mathrm{~m}$ & $\begin{array}{c}0.024 \mathrm{~m} \\
(-4.0 \%)\end{array}$ & $\begin{array}{c}0.033 \mathrm{~m} \\
(+32.0 \%)\end{array}$ & $\begin{array}{c}0.017 \mathrm{~m} \\
(-32.0 \%)\end{array}$ & $\begin{array}{c}0.020 \mathrm{~m} \\
(-20.0 \%)\end{array}$ \\
\cline { 2 - 7 } & $1: 2$ & $0.030 \mathrm{~m}$ & $\begin{array}{c}0.029 \mathrm{~m} \\
(-3.4 \%)\end{array}$ & $\begin{array}{c}0.033 \mathrm{~m} \\
(+10.0 \%)\end{array}$ & $\begin{array}{c}0.019 \mathrm{~m} \\
(-36.6 \%)\end{array}$ & $\begin{array}{c}0.020 \mathrm{~m} \\
(-33.0 \%)\end{array}$ \\
\hline
\end{tabular}

The changing level of damping of the system as well as individual elements is shown in Figure 10 for increasing levels of ductility. The four lines show the damping of the bare frame, the frame-cladding system and the contribution from each component to the system.

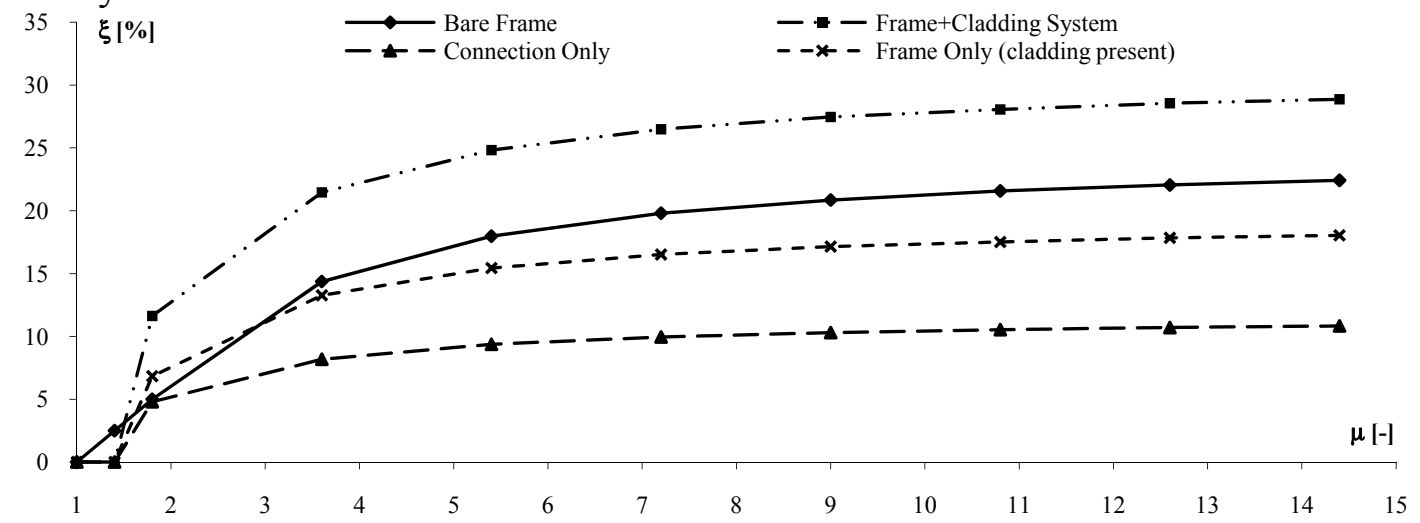

Figure 10: Damping vs. ductility for connection governing cases 
Member demand envelopes along one of the beams are shown for a frame ratio of 1:1 with fixed beam connections. Again, the general shape of these plots is similar for all analyses where connection failure governs; so the full results have been tabulated in Table 3 for comparison purposes. The values in the table represent the largest moment and shear force in the beam or column at the cladding panel connection.
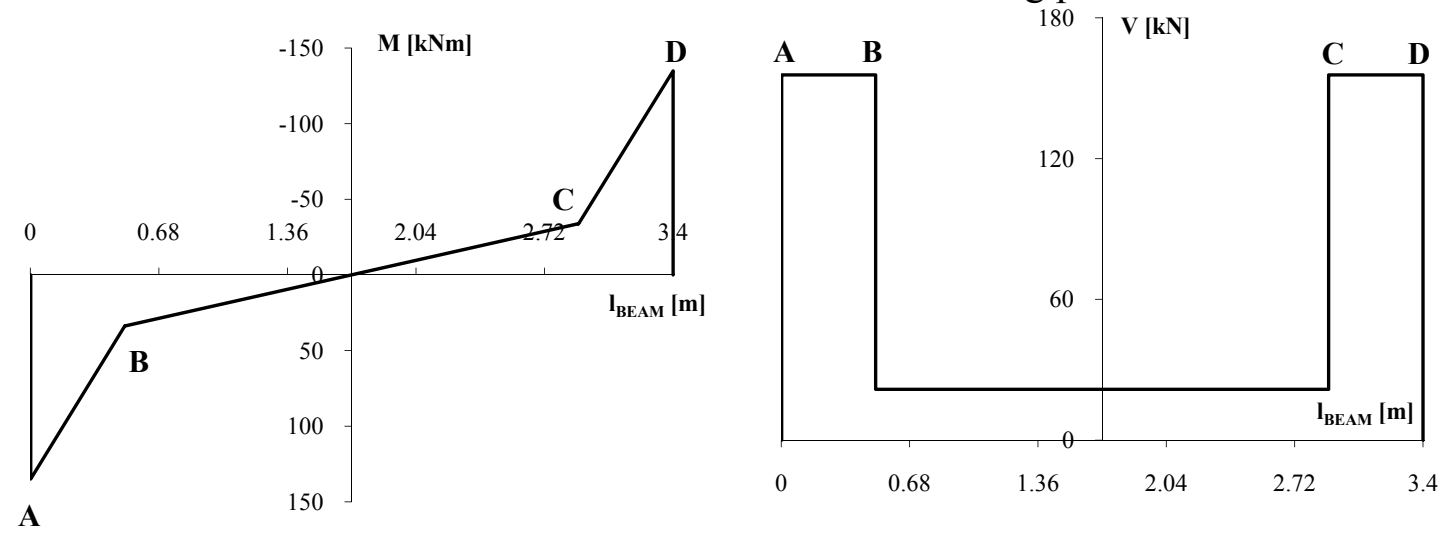

Figure 11: Moment/shear envelope for connection governing cases (refer to Figure 7 (left), where $B$ and $C$ are locations of panel connections)

Table 3: Full results for moment/shear envelope

\begin{tabular}{|c|c|c|c|c|c|c|}
\hline Beam Connection & \multicolumn{2}{|c|}{ Bare Frame } & \multicolumn{2}{c|}{ Fixed } & \multicolumn{2}{c|}{ Slotted } \\
\hline Frame Ratio & $\mathrm{M}$ & $\mathrm{V}$ & $\mathrm{M}$ & $\mathrm{V}$ & $\mathrm{M}$ & $\mathrm{V}$ \\
\hline $1: 1$ & $85.2 \mathrm{kNm}$ & $71.0 \mathrm{kN}$ & $-69.5 \%$ & $-69.4 \%$ & $-68.8 \%$ & $-68.7 \%$ \\
\hline $1: 1.5$ & $102.4 \mathrm{kNm}$ & $46.5 \mathrm{kN}$ & $-70.9 \%$ & $-70.8 \%$ & $-70.6 \%$ & $-70.5 \%$ \\
\hline $1: 2$ & $110.8 \mathrm{kNm}$ & $34.5 \mathrm{kN}$ & $-71.8 \%$ & $-71.6 \%$ & $-71.7 \%$ & $-71.6 \%$ \\
\hline Column Connection & \multicolumn{2}{|c|}{ Bare Frame } & \multicolumn{2}{|c|}{ Fixed } & \multicolumn{2}{c|}{ Slotted } \\
\hline Frame Ratio & $\mathrm{M}$ & $\mathrm{V}$ & $\mathrm{M}$ & $\mathrm{V}$ & $\mathrm{M}$ & $\mathrm{V}$ \\
\hline $1: 1$ & $58.8 \mathrm{kNm}$ & $57.9 \mathrm{kN}$ & $-13.1 \%$ & $-13.3 \%$ & $-6.0 \%$ & $-6.6 \%$ \\
\hline $1: 1.5$ & $58.7 \mathrm{kNm}$ & $57.9 \mathrm{kN}$ & $-14.7 \%$ & $-14.2 \%$ & $-9.4 \%$ & $-9.5 \%$ \\
\hline $1: 2$ & $58.5 \mathrm{kNm}$ & $57.9 \mathrm{kN}$ & $-15.0 \%$ & $-14.2 \%$ & $-12.1 \%$ & $-12.3 \%$ \\
\hline
\end{tabular}

\section{Part 2: Panel/Frame Governing Analyses}

For these analyses the connections are assumed to be infinitely stiff and to remain elastic. This assumption is valid for cladding panels of low strength, however, for higher strength panels, the force transmitted through the connections becomes very large and as such would be unrealistic if a typical cladding connection is used. This case would be applicable to a panel that is fixed in place with grouted connections or intended to behave similarly to a shear wall. The connection configuration is varied in the same way as part 1 . The panel strength is varied from a low strength, typical of aerated concrete, up to a high concrete strength (from $4 \mathrm{MPa}$ to $30 \mathrm{MPa}$ ). The 'medium' strength panel represents the failure transition point from panel failure to frame failure. The frame's height to span ratio is kept fixed.

\section{Results}

Shown in Figure 12 are force-displacement plots of the push-over and push-pull analysis results. These particular plots are for a frame ratio of 1:1 with fixed beam connections. The general shape of these plots is similar for all analyses where panel/frame failure governs. The frames base shear and deflection at yield for all of the analyses can be seen in Table 4 in order to compare the results and failure mechanism. 
The push-over plot in Figure 12 (left) shows the different behavior of the three different panel strengths particularly the change in failure mechanism. The low strength panel fails before the frame so the overall resistance provided by the system returns to that provided by the frame alone. The theoretical medium strength panel shows the same behavior as the high strength panel up to yielding. If the panel is weaker than this failure transition strength then it exhibits the same behavior as the low strength panel, decaying back to the frame strength. However, if the panel is stronger it results in the beam yielding in flexure at the connection point and eventually leads to failure of the beam at this point.
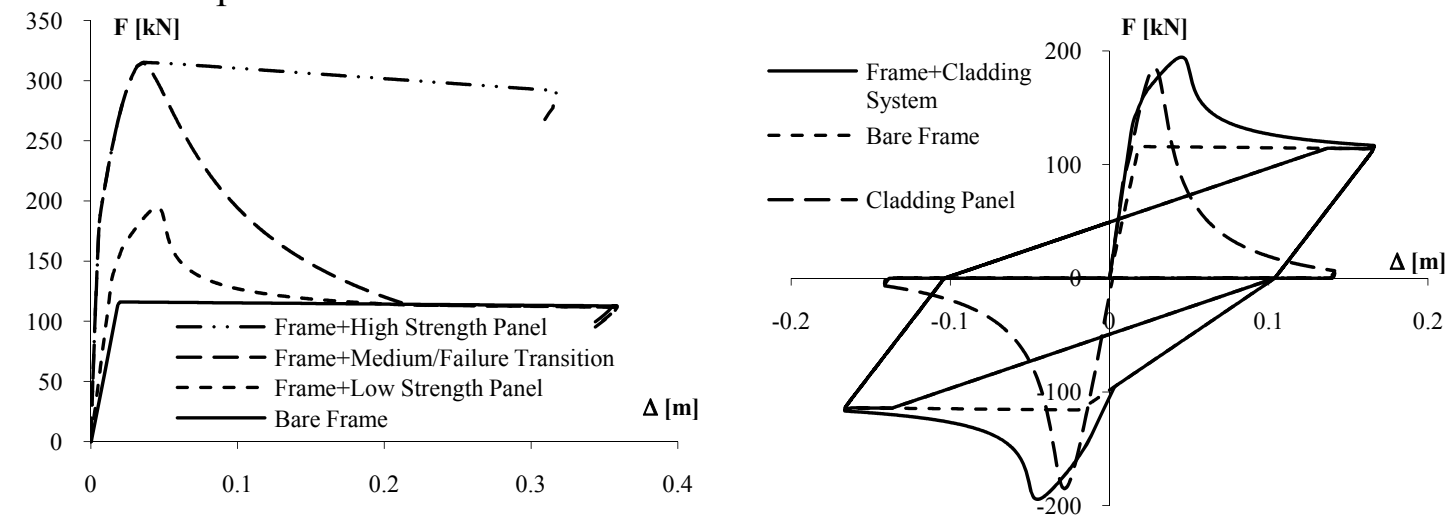

Figure 12: Force-displacement analyses for panel/frame governing cases

The push-pull analyses can only be conducted for cases where the frame does not fail, i.e. panel failure. As shown in Figure 12 (right) after one cycle in either direction, once the compressive strut representing the panel is effectively destroyed then the behavior returns to that of the bare frame.

When the panel is attached to the column the failure mechanism was found to always be in the panel however this result is not very realistic because of the large shear forces in the column. Since the model herein adopted does not take into account shear failure in the structural elements this failure mechanism is likely being missed.

Table 4: Parametric results for push-over analyses of panel/frame governing cases

\begin{tabular}{|c|c|c|c|c|c|}
\cline { 2 - 6 } \multicolumn{2}{c|}{} & Bare Frame & Low strength & $\begin{array}{c}\text { Medium strength } \\
\text { Failure transition }\end{array}$ & High strength \\
\hline \multirow{4}{*}{$\begin{array}{c}\text { Fixed beam } \\
\text { connections }\end{array}$} & Base shear at yield & $116.1 \mathrm{kN}$ & $\begin{array}{c}194.6 \mathrm{kN} \\
(+67.6 \%)\end{array}$ & $\begin{array}{c}314.8 \mathrm{kN} \\
(+171.1 \%)\end{array}$ & $\begin{array}{c}314.8 \mathrm{kN} \\
(+171.1 \%)\end{array}$ \\
\cline { 2 - 6 } & Frame deflection at yield & $0.020 \mathrm{~m}$ & $\begin{array}{c}0.045 \mathrm{~m} \\
(+128.3 \%)\end{array}$ & $\begin{array}{c}0.036 \mathrm{~m} \\
(+83.0 \%)\end{array}$ & $\begin{array}{c}0.044 \mathrm{~m} \\
(+127.4 \%)\end{array}$ \\
\cline { 2 - 6 } & Failure mechanism & STRUCTURE & PANEL & PANEL/STRUCTURE & STRUCTURE \\
\hline $\begin{array}{c}\text { Fixed } \\
\text { column } \\
\text { connections }\end{array}$ & Base shear at yield & $116.1 \mathrm{kN}$ & $\begin{array}{c}186.5 \mathrm{kN} \\
(+60.6 \%)\end{array}$ & $\begin{array}{c}300.2 \mathrm{kN} \\
(+158.6 \%)\end{array}$ & $\begin{array}{c}662.2 \mathrm{kN} \\
(+470.4 \%)\end{array}$ \\
\cline { 2 - 6 } & Frame deflection at yield & $0.020 \mathrm{~m}$ & $\begin{array}{c}0.024 \mathrm{~m} \\
(+20.0 \%)\end{array}$ & $\begin{array}{c}0.045 \mathrm{~m} \\
(+132.0 \%)\end{array}$ & $\begin{array}{c}0.062 \mathrm{~m} \\
(+216.8) \%\end{array}$ \\
\cline { 2 - 6 } & Failure mechanism & STRUCTURE & PANEL & PANEL & PANEL \\
\hline
\end{tabular}

\section{CONCLUSIONS}

The results show that there is an increase in strength of at least $10-20 \%$ for all systems when the influence of cladding panels is taken into account. This contribution is greater when panels are attached to the columns rather than to the beams because the beams deflect more and activate the connections later. There is also an increase in hysteretic damping for all systems. Frame height to span ratio does not affect the yield force of the system greatly however, increasing it does allow for a higher 
deflection/drift of the system at yield. When both panel and connections are strong the capacity of the system is increased but the ductility is decreased. The model limits the additional hysteretic damping provided by the panel crushing to one cycle, when in reality the panel would still be dissipative, but this dissipation is not reliable.

It is apparent that it is more advantageous to have and thus design for a connection governed failure mechanism than a failure mechanism which is governed by either the panel or the frame. Connection governed failure allows greater damping, strength and stiffness over many cycles. However this assumes that the tie-back connections are designed to accommodate a large level of ductility. Also in terms of the cost and ease of repairs; the substitution of failed connections is seen to be more favorable than having to replace entire damaged panels.

To improve the analyses, the consideration of shear failure in the beams, columns and beam-column joint is vital. It is also worth considering other typologies of connections with different behavior, e.g. non-ductile.

\section{REFERENCES}

Brown, M.D., Sankovich, C.L., Bayrak, O., and Jirsa, J.O. (2006). "Behavior and Efficiency of Bottle-Shaped Struts”. ACI Structural Journal, 103(3), 348-355.

Carr, A. (2004). "Ruaumoko Programme for Inelastic Dynamic Analysis - User Manual". Department of Civil Engineering, University of Canterbury.

Charleson, A. (2008). "Seismic Design for Architects: Outwitting the Quake." Architectural Press.

Cohen, J.M. (1993). "Feasibility of two-level seismic retrofit using an energy dissipating cladding system". Cladding Research Institute.

Crisafulli, F.J. (1997). "Seismic Behaviour of Reinforced Concrete Structures with Masonry Infills". Ph.D. Thesis, University of Canterbury.

De Matteis, G. (2005). "Effect of Lightweight Cladding Panels on the Seismic Performance of Moment Resisting Steel Frames". Engineering Structures, 27 (11)

FEMA 356. (2000). "Prestandard and Commentary for the Seismic Rehabilitation of Building”. FEMA.

Goodno, B.J., Meyyappa, M., and Nagarajaiah, S. (1988). "A Refined Model for Precast Cladding and Connections". Proceedings, $9^{\text {th }}$ World Conference in Earthquake Engineering, Tokyo, Japan, pp. 195-200.

McMullin, K., Wong, Y., Choi, C. and Chan, K. (2004). "Seismic performance thresholds of precast concrete cladding connections". 13 th World Conference on Earthquake Engineering, Vancouver, Canada

Okazaki, T., Nakashima, M., Suita, K., \& Matusmiya, T. (2007). "Interaction between Cladding and Structural Frame Observed in a Full-Scale Steel Building Test". Earthquake Engineering \& Structural Dynamics , 36 (1)

Otani, S., Sake, A. (1974). "A Computer Program for Inelastic Response of R/C Frames to Earthquakes". Report UILU-ENG-74-2029, Civil Engineering Studies, Univ. Of Illinois at Urbana-Champaign.

Pinelli, J.P., Craig, J. I., \& Goodno, B. J. (1995). "Energy-Based Seismic Design of Ductile Cladding Systems". Journal of Structural Engineering, 121(3)

Priestley, M.J.N. (2000). "Performance Based Seismic Design". 12 th World Conference on Earthquake Engineering, Auckland, New Zealand

SEAOC Vision 2000 Committee. (1995). Performance-based seismic engineering. Sacramento, California: Structural Engineers Associate of California. 